\title{
RESEARCH TREND AND STATUS OF FORESTRY BASED ON ESSENTIAL SCIENCE INDICATORS DURING 2010-2020: A BIBLIOMETRIC ANALYSIS
}

\author{
YUAN, B. Z. ${ }^{1 *}-$ SUN, J. ${ }^{2}$ \\ ${ }^{1}$ College of Plant Science and Technology, Huazhong Agricultural University, Wuhan City, \\ 430070 Hubei Province, PR China \\ ${ }^{2}$ Library of Huazhong Agricultural Universillty, Wuhan City, 430070 Hubei Province, PR China \\ *Corresponding author \\ e-mail:yuanbz@mail.hzau.edu.cn \\ (Received $8^{\text {th }}$ Jun 2021; accepted $20^{\text {th }}$ Sep 2021)
}

\begin{abstract}
This study analyzed 302 top papers in the subject category of Forestry from 2010 to 2020 , which include 300 highly cited papers and 3 hot papers. All papers were written in English, belonging to 1,567 authors, 694 organizations and 74 countries/territories, published in 35 journals and book series. The top five Journals were Agricultural and Forest Meteorology, Forest Ecology and Management, Forests, Tree Physiology and Forest Policy and Economics. Top five countries and regions were USA, Germany, Canada, France and Peoples R China. Top five organizations were US Forest Serv, Chinese Acad Sci, INRA, Swedish Univ Agr Sci and Univ Freiburg. Among the all authors, Bauhus, Juergen from Univ Freiburg of Germany provided the highest number in 6 papers. All keywords were separated into seven clusters for different research topics. Visualizations offered exploratory information on the current state in a scientific field or discipline as well as indicated possible developments in the future.
\end{abstract}

Keywords: forestry category, top papers, visualization, VOSviewer

\section{Introduction}

According to the category description for Forestry in Scope Notes of Science Citation Index Expanded, it covers resources concerning the science and technology involved in establishing, maintaining and managing forests for various uses, including wood production, water resource management, wildlife conservation and recreation (Clarivate, 2021. InCites Journal Citation Reports).

Bibliometrics technique has been adopted analyzing the forestry category on Web of Science (WoS) which included the following subjects, bibliometric analysis of forestry and forest research (Polinko and Coupland, 2021), assessing the scientific productivity of Italian forest researchers (Chirici, 2012), models for temperate forest management (Ordoñez and Galicia, 2020), evaluation of the status of Picea research and research hotspots (Duan et al., 2020), community forestry research in Canada (Bullock and Lawler, 2015), ecological restoration in Brazilian biomes (Guerra et al., 2020), wood modification and environmental impact assessment (Burnard et al., 2017), forest ecosystem services (Aznar-Sanchez et al., 2018), first decade bibliometric analysis of journal of Forests (Uribe-Toril et al., 2019), remote sensing applied in forest management to optimize ecosystem services (Abad-Segura et al., 2020), spatiotemporal analysis of forest modeling in Mexico (Martínez-Santiago et al., 2017), evaluation of the research on common forest management (Romanelli and Boschi, 2019), trees and parks as "the lungs of cities" (Xing and Brimblecombe, 2020). 
Bibliometrics technique has analyzed other WoS category documents, such as, classic publications in WoS category of orthopedics (Li et al., 2019), emergency medicine (Ho, 2021), materials science (Ho, 2014), horticulture (Kolle et al., 2017), dentistry, oral surgery and medicine from 2007 to 2016 (Yeung and Leung, 2018), dance (Ho and Ho, 2015), water resources (Chuang et al., 2011), environmental sciences (Khan and Ho, 2012), education and educational research (Ivanović and Ho, 2019).

Top papers are the sum of hot papers and highly cited papers, based on Clarivate Analytics' Essential Science Indicators (ESI). The ESI database is widely used to assess scientific outputs. Highly cited paper is a paper that belongs to the top $1 \%$ of papers in a research field published in a specified year. The $1 \%$ is determined by the highly cited threshold calculated for the research field in the specified year. Hot paper is a paper published in the past two years that received a number of citations in the most recent two-month period that places it in the top $0.1 \%$ of papers in the same field. Some papers focused on as Economics and Business (Zhang et al., 2018), operations research and management science (Liao et al., 2019), environmental sciences (Ma et al., 2020), macro-level collaboration network analysis and visualization (Yang et al., 2020). Sun and Yuan have analyzed the top papers in the world rice research (Sun and Yuan, 2020a), library and information science (Sun and Yuan, 2020b), water Resources (Sun and Yuan, 2020c), agronomy category (Sun and Yuan, 2021), green and sustainable science and technology (Yuan and Sun, 2019) and scientific research on maize or corn (Yuan and Sun, 2020a, b).

The purpose of this paper was to use bibliometric methods to analyze the top papers in the subject category of Forestry during 11 years period from 2010 to 2020 through publication year, category, author, affiliations, country, journals, all keywords and other key features. Co-authorship network visualization of author, organizations and countries, co-occurrence network visualization of all keywords were done by VOSviewer. Special attention will be dedicated to research topics and research fronts.

\section{Materials and methods}

\section{Essential science indicators (ESI)}

Essential science indicators (ESI) is a unique compilation of performance statistics and trends extrapolated from counts of articles published in scholarly journals and the citations to those articles. ESI is an analytical tool that helps you identify topperforming research in Web of Science (WoS) Core Collection. Article counts for ESI are derived from journals indexed in WoS Core Collection (SCIE and SSCI only) over a 11-year period. Citation counts for these articles are derived from journals indexed in WoS Core Collection (SCIE, SSCI and Arts and Humanities Citation Index). Each journal is assigned to one of 22 research fields. In ESI a journal can be assigned to only one field. Journals such as Science and Nature are categorized as multidisciplinary since they publish research in many different fields. As a result, papers published in these multidisciplinary journals are assigned to a field based on the representation of the cited journals. For example, if the majority of cited references in the paper are to neuroscience journals, the paper is then categorized as neuroscience (Clarivate, Version 3.0, Essential Science Indicators Help, 2021).

Here, the Essential Science Indicators database has been updated as of March 25, 2021, to cover an 11-year period from January 1, 2010 to December 31, 2020. Papers are defined as regular scientific articles and review articles. 


\section{Data collection}

Data collection was completed on the single day on May 1, 2021 to avoid the bias. We first conducted an advanced search in the WoS category (WC) of Forestry and publication year (PY) from 2010 to 2020. The query as following: (WC = Forestry) AND (PY 2010-2020).

The results were used to identify the top papers of the highly cited papers and hot papers in field. There are 302 top papers from WoS Core Collection. Full record and cited references of the included papers were extracted and imported into VOSviewer (Leiden University, Leiden, the Netherlands) for further citation analysis. The impact factors (IF 2019 and IF 5year) were taken from the Journal Citation Report (JCR 2019) published in 2020, which had the latest data available.

\section{VOSviewer}

VOSviewer were used to show the international collaboration between the authors, organizations, countries and the research trends through all keywords (Van Eck and Waltman, 2010). Visualizations (network and overlay) using program VOSviewer are conducted on WoS data in order to determine co-occurrence and clusters of connected publications, country input and author collaboration (co-authorship) as well as clusters of interrelated research topics (text data). In this paper, default parameters values of the VOSviewer are usually used in the analysis. Items are represented by a label and a circle. The size of circles reflects the weight of an item. Some items are not displayed in avoidance of overlapping. The colors in network visualization (text maps) represent clusters of similar items as calculated by the program. Distance between the items indicates the strength of relationships.

\section{Results and discussion}

\section{Document type and language of publication}

Based on Clarivate Analytics's WoS Index, there were total 302 top papers of the Forestry category during the period from January, 2010 to December, 2020. All of 302 top papers were identified in SCIE (302), SSCI (36), and CPCI-S (6). The document types of all 302 top papers were articles $(213,70.53 \%)$, reviews $(89,29.47 \%)$ and proceedings papers $(6,1.987 \%)$. Among the all 302 top papers, there were 3 hot papers and 300 the highly cited papers that means 2 papers were both the hot papers and the highly cited papers. All papers were published in English. The English was dominating language from the WoS, and scholars tended to publish their articles in English as they want them to be widely accepted (Khan et al., 2020).

\section{Publication output}

With the aim of knowing the research status and trend, Figure 1 showed the top paper of Forestry category between 2010 and 2020. The mean publication was 27.45 each year, and the highest value was 40 in 2020. An increase in the number of cited references indicated that there are more citing or cited publications. The number of citations to a paper is considered a good quantitative measure of a paper's impact. The $h$-index was initially proposed as a measure of a researcher's scientific output based on counting the number of publications $(\mathrm{N})$ by that researcher cited $\mathrm{N}$ or more times 
(Hirsch, 2005). For the total 302 papers, the $h$-index was 140, and the average citation per item was 153.61.

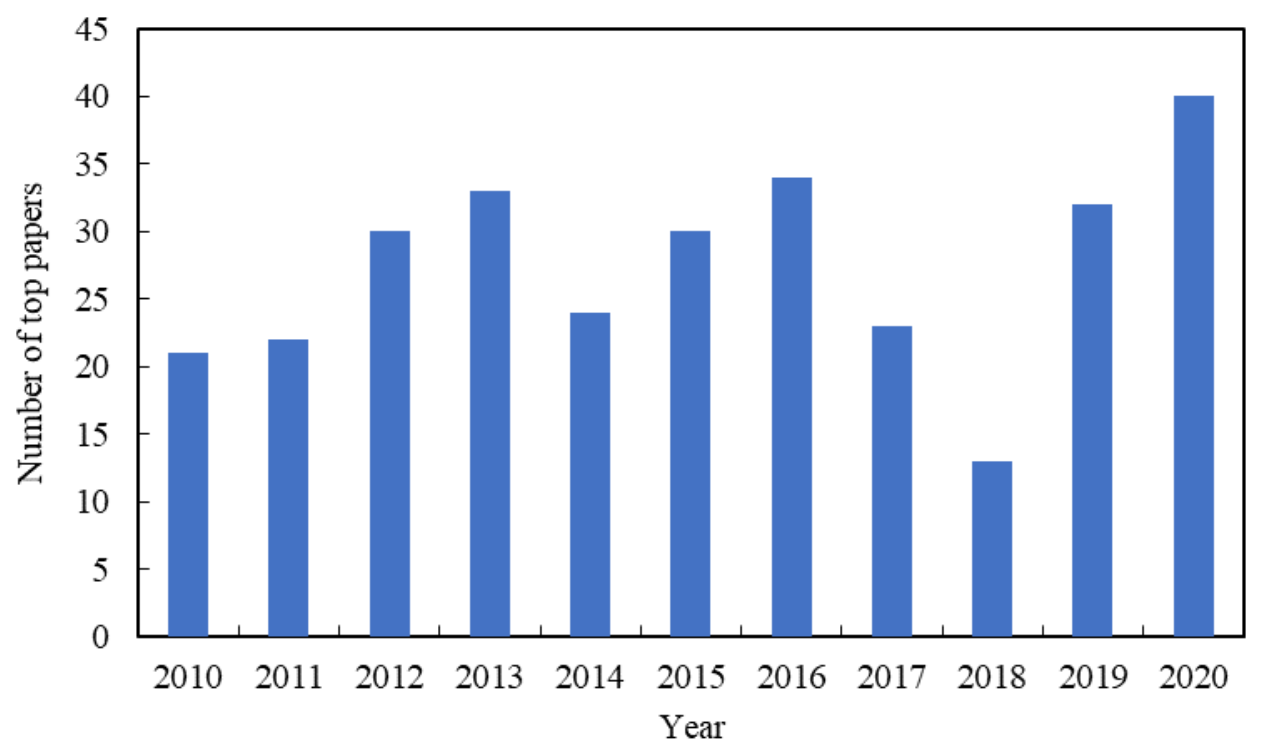

Figure 1. Number of published top papers of Forestry category from 2010 to 2020

\section{Web of Science categories and research areas}

Each paper indexed by the WoS belongs to one or more subject categories. There were total $14 \mathrm{WoS}$ subject categories and 11 research areas including Forestry categories (Table 1). Among these, the top six categories included Forestry (302 papers, $100 \%$ of 302 papers), Agronomy (69, 22.848\%), Meteorology Atmospheric Sciences $(66,21.854 \%)$, Plant Sciences $(31,10.265 \%)$, Ecology $(23,7.616 \%)$ and Environmental Studies $(23,7.616 \%)$. The top six research areas included Forestry (302 papers, $100 \%$ of 302 papers), Agriculture (73, 24.172\%), Meteorology Atmospheric Sciences (66, 21.854\%), Environmental Sciences Ecology (46, 15.232\%), Plant Sciences (31, $10.265 \%)$ and Business Economics $(31,10.265 \%)$. Journals or papers may be classified into two or more categories in the WoS, showed the multidisciplinary character of this research field (Elango and Ho, 2018). In WoS, publications were also mapped to WoS categories which were more detailed than areas (Stopar et al., 2021).

\section{Core journals}

Based on JCR 2019 data (published in 2020), there were 68 journals of the WoS categories for Forestry. All the 302 publications were published in 35 journals and book series. The top 20 core journals were displayed in Table 2 with total articles each more than four top papers, Journal impact factor as IF 2019 and IF 5 year, rank and Quartile in Forestry category.

The top 5 journals, top 10 journals, top 15 journals and top 20 journals published about $61.589 \%, 75.497 \%, 85.101 \%$ and $91.726 \%$ of the total top papers, respectively. The top five Journals are Agricultural and Forest Meteorology $(66,21.854 \%)$, Forest Ecology and Management $(65,21.523 \%)$, Forests $(23,7.616 \%)$, Tree Physiology (17, $5.629 \%)$ and Forest Policy and Economics (15, 4.967\%), each published more than 15 
papers. Based on results of Table 2, among the top 20 journals, fourteen journals were in Quartile 1, six journals were in Quartile 2. White-Gibson et al. (2019) had also demonstrated the importance of publishing articles in the English language in a high IF journals.

Table 1. WoS categories and research areas for forestry category during 2010-2020

\begin{tabular}{|c|c|c|c|c|c|c|}
\hline \multirow[b]{2}{*}{ Rank } & \multicolumn{3}{|l|}{ WoS categories } & \multicolumn{3}{|c|}{ Research areas } \\
\hline & Categories & $\begin{array}{c}\text { No. } \\
\text { papers }\end{array}$ & $\begin{array}{l}\% \text { Total } \\
\text { papers }\end{array}$ & Areas & $\begin{array}{c}\text { No. } \\
\text { papers }\end{array}$ & $\begin{array}{c}\text { \% Total } \\
\text { papers }\end{array}$ \\
\hline 1 & Forestry & 302 & 100 & Forestry & 302 & 100 \\
\hline 2 & Agronomy & 69 & 22.848 & Agriculture & 73 & 24.172 \\
\hline 3 & Meteorology atmospheric sciences & 66 & 21.854 & Meteorology atmospheric sciences & 66 & 21.854 \\
\hline 4 & Plant sciences & 31 & 10.265 & Environmental sciences ecology & 46 & 15.232 \\
\hline 5 & Ecology & 23 & 7.616 & Plant sciences & 31 & 10.265 \\
\hline 6 & Environmental studies & 23 & 7.616 & Business economics & 15 & 4.967 \\
\hline 7 & Economics & 15 & 4.967 & Urban studies & 8 & 2.649 \\
\hline 8 & Urban studies & 8 & 2.649 & Materials science & 6 & 1.987 \\
\hline 9 & Materials science paper wood & 6 & 1.987 & Genetics heredity & 4 & 1.325 \\
\hline 10 & Genetics heredity & 4 & 1.325 & Physical geography & 3 & 0.993 \\
\hline 11 & Horticulture & 4 & 1.325 & Zoology & 1 & 0.331 \\
\hline 12 & Geography physical & 3 & 0.993 & & & \\
\hline 13 & Materials science textiles & 1 & 0.331 & & & \\
\hline 14 & Zoology & 1 & 0.331 & & & \\
\hline
\end{tabular}

Table 2. Top 20 core journals on forestry category research indexed in the WoS

\begin{tabular}{|c|c|c|c|c|c|c|c|}
\hline Rank & Journal & $\mathbf{T P}$ & Ratio & IF 2019 & IF 5year & QC & QR \\
\hline 1 & Agricultural and Forest Meteorology & 66 & 21.854 & 4.651 & 5.142 & Q1 & 2 \\
\hline 2 & Forest Ecology and Management & 65 & 21.523 & 3.17 & 3.581 & Q1 & 5 \\
\hline 3 & Forests & 23 & 7.616 & 2.221 & 2.484 & Q1 & 17 \\
\hline 4 & Tree Physiology & 17 & 5.629 & 3.655 & 4.33 & Q1 & 4 \\
\hline 5 & Forest Policy and Economics & 15 & 4.967 & 3.139 & 3.085 & Q1 & 6 \\
\hline 6 & Journal of Vegetation Science & 12 & 3.974 & 2.698 & 3.177 & Q1 & 7 \\
\hline 7 & Canadian Journal of Forest Research & 8 & 2.649 & 1.812 & 2.162 & Q2 & 25 \\
\hline 8 & Urban Forestry Urban Greening & 8 & 2.649 & 4.021 & 4.468 & Q1 & 3 \\
\hline 9 & Current Forestry Reports & 7 & 2.318 & 4.972 & 5.115 & Q1 & 1 \\
\hline 10 & European Journal of Forest Research & 7 & 2.318 & 2.451 & 2.581 & Q1 & 12 \\
\hline 11 & Forestry & 7 & 2.318 & 2.293 & 3.036 & Q1 & 14 \\
\hline 12 & Journal of Forestry Research & 6 & 1.987 & 1.689 & 1.475 & Q2 & 31 \\
\hline 13 & Journal of Plant Ecology & 6 & 1.987 & 1.833 & 2.299 & Q2 & 23 \\
\hline 14 & Annals of Forest Science & 5 & 1.656 & 2.033 & 2.758 & Q2 & 21 \\
\hline 15 & International Journal of Wildland Fire & 5 & 1.656 & 2.627 & 2.939 & Q1 & 9 \\
\hline 16 & Applied Vegetation Science & 4 & 1.325 & 2.574 & 2.903 & Q1 & 10 \\
\hline 17 & IAWA Journal & 4 & 1.325 & 1.627 & 1.966 & Q2 & 34 \\
\hline 18 & Journal of Forestry & 4 & 1.325 & 2.342 & 2.681 & Q1 & 13 \\
\hline 19 & New Forests & 4 & 1.325 & 2.24 & 2.631 & Q1 & 16 \\
\hline 20 & Tree Genetics Genomes & 4 & 1.325 & 2.081 & 2.262 & Q2 & 20 \\
\hline
\end{tabular}

TP: Total publications; Ratio: Ratio of 302 (\%); IF 2019: journal impact factor in 2019; IF5 year: journal impact factor of 5 years; QC: Quartile in Category; QR: Quartile rank of 68 journals in Forestry 
According to the publication data in the citation of 35 journals, they all meet the thresholds of one publication, but only 23 journals were connected to each other. The network of citation in the field of Forestry category based on WoS was shown seven clusters with different colors in Figure 2, the size of circles reflected a total number of journal publication records. Journals in the same cluster usually suggested that they published the similar content papers and had close relations with each other.

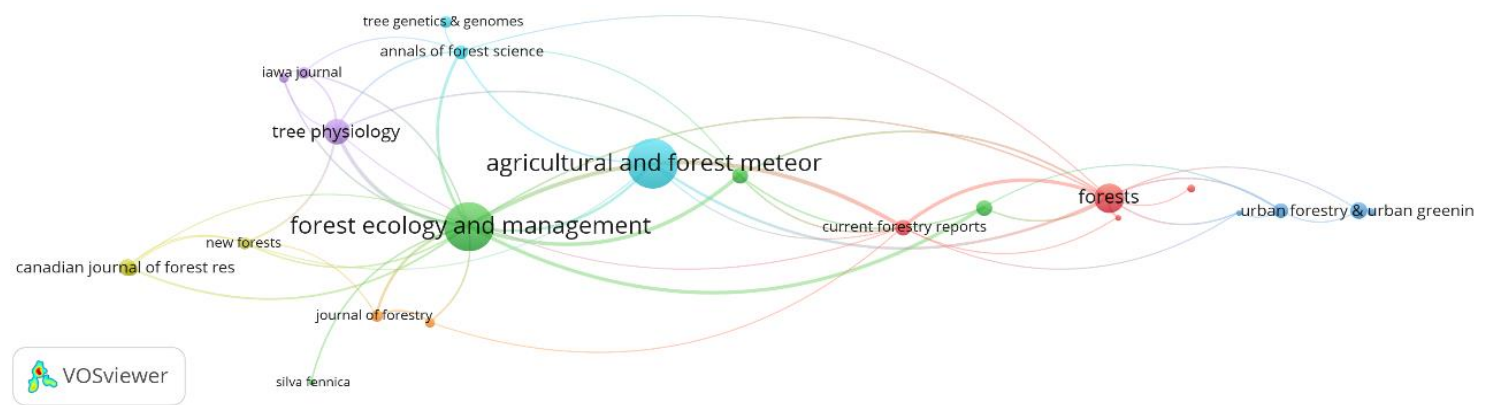

Figure 2. Network visualization maps of citation journals in the field of Forestry category based on WoS with 23 nodes and 7 clusters

\section{Authors co-authorship analysis}

In general, internationally collaborative articles had the highest visibility and scientific impact, followed by inter-institutional collaborative articles, single-country articles and single-author articles, respectively. A total of 1,567 authors had the 302 publications, and 127 authors met the thresholds of two publications, but only 23 authors were connected with each other. The network of authorship in the field of Forestry category based on WoS represented in Figure 3, the size of circles reflected a total number of records. Authors in the same cluster usually suggested that they studied in a similar field or worked at same institute or had close cooperation with each other.

The detail of author information published articles in the field of Forestry category from 2010 to 2020 along with citation, average citations, organization-enhanced and countries were provided in Table 3. The top eight authors published more than four papers. Though we combined the same author with the different spell, but the total number of authors were calculated separately. Among the all authors, Bauhus, Juergen from Univ Freiburg of Germany gave the most 6 papers.

The organization of the author was the latest institute. There were three authors from USA, the organizations were Colorado State Univ, Univ Washington and USDA FS; two authors from Germany, the organizations were Univ Freiburg and Tech Univ Munich; one author was from the Swiss Fed Inst Forest Snow and Landscape Res WSL of Switzerland; one author was from University of Kurdistan of Iran; one author was from Universidade Estadual Paulista of Brazil. The five authors with the higher average citations per paper were Forrester, David I., Pretzsch, Hans, Franklin, Bauhus, Juergen and Hessburg, Paul F., et al.

\section{Countries/regions co-authorship analysis}

There were 74 countries or regions that contributed 302 papers in the field of Forestry category from 2010 to 2020. Table 4 represented the top 20 countries or regions that published more than 10 papers, and the cluster, total link strength, 
citations and average citations. Among the 20 countries, USA, Germany, Canada, France and Peoples R China were the major article contributors. In case of average citations, Spain, Italy, Switzerland, France and Australia showed the higher citations per paper.

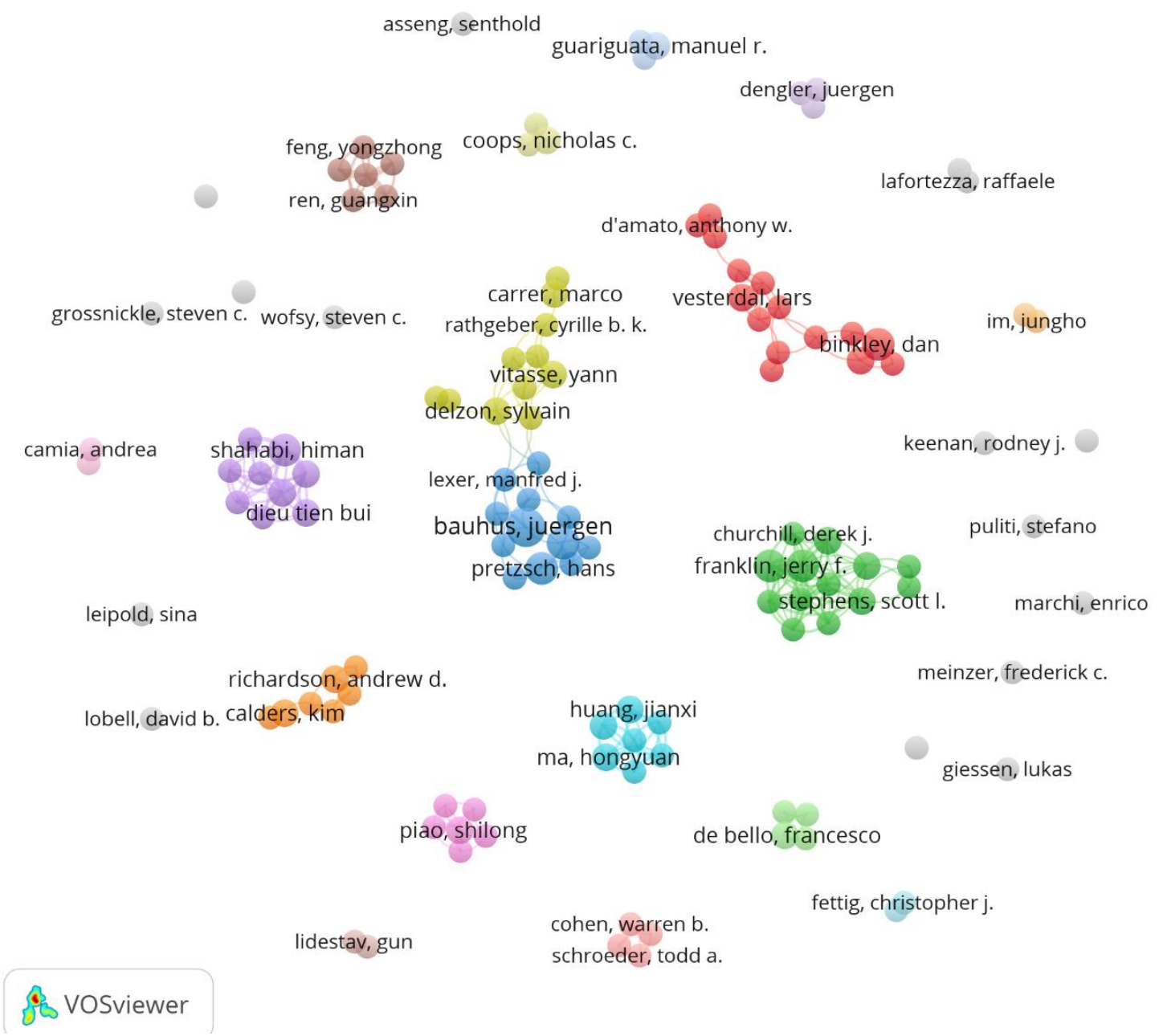

Figure 3. Network visualization map of top authors in Forestry category from 2010 to 2020. Cooperation based on co-authorship between authors. Network visualization map of authors with minimum productivity of two publications in the studied field and exist within a collaborative research group

Table 3. The top eight most prolific authors published papers in the field of Forestry category from 2010 to 2020

\begin{tabular}{c|c|c|c|c|c|c}
\hline Rank & Author & Papers & Citations & $\begin{array}{c}\text { Average } \\
\text { citations }\end{array}$ & Organizations & Country \\
\hline $\mathbf{1}$ & Bauhus, Juergen & 6 & 751 & 125.17 & Univ Freiburg & Germany \\
$\mathbf{2}$ & Binkley, Dan & 4 & 319 & 79.75 & Colorado State Univ & USA \\
$\mathbf{3}$ & Forrester, David I. & 4 & 698 & 174.50 & Swiss Fed Inst Forest Snow and Landscape Res WSL & Switzerland \\
$\mathbf{4}$ & Franklin, Jerry F. & 4 & 572 & 143.00 & Univ Washington & USA \\
$\mathbf{5}$ & Hessburg, Paul F. & 4 & 497 & 124.25 & USDA FS & USA \\
$\mathbf{6}$ & Pretzsch, Hans & 4 & 575 & 143.75 & Tech Univ Munich & Germany \\
$\mathbf{7}$ & Shahabi, Himan & 4 & 195 & 48.75 & University of Kurdistan & Iran \\
$\mathbf{8}$ & Stape, Jose L. & 4 & 319 & 79.75 & Universidade Estadual Paulista & Brazil \\
\hline
\end{tabular}


Table 4. Top 20 countries/regions publishing top papers in the field of Forestry category from 2010 to 2020

\begin{tabular}{c|c|c|c|c|c|c}
\hline Rank & Countries/regions & Records & Cluster & Total link strength & Citations & Average citations \\
\hline 1 & USA & 122 & 2 & 223 & 23822 & 195.26 \\
2 & Germany & 55 & 1 & 223 & 7669 & 139.44 \\
3 & Canada & 47 & 2 & 117 & 10399 & 221.26 \\
4 & France & 45 & 3 & 181 & 10811 & 240.24 \\
5 & Peoples R China & 44 & 2 & 69 & 8921 & 202.75 \\
6 & Australia & 41 & 3 & 137 & 9748 & 237.76 \\
7 & Italy & 40 & 4 & 167 & 10443 & 261.08 \\
8 & Switzerland & 33 & 1 & 172 & 7957 & 241.12 \\
9 & England & 28 & 3 & 133 & 3799 & 135.68 \\
10 & Spain & 26 & 1 & 157 & 6963 & 267.81 \\
11 & Austria & 24 & 1 & 163 & 4302 & 179.25 \\
12 & Sweden & 23 & 1 & 111 & 2635 & 114.57 \\
13 & Netherlands & 20 & 3 & 119 & 3896 & 194.80 \\
14 & Finland & 19 & 4 & 66 & 2953 & 155.42 \\
15 & Brazil & 18 & 3 & 49 & 2611 & 145.06 \\
16 & Czech Republic & 18 & 1 & 86 & 2386 & 132.56 \\
17 & Japan & 15 & 2 & 61 & 2095 & 139.67 \\
18 & Scotland & 14 & 1 & 71 & 1953 & 139.50 \\
19 & Denmark & 10 & 1 & 47 & 1359 & 135.90 \\
20 & Norway & 10 & 2 & 39 & 948 & 94.80 \\
\hline
\end{tabular}

There were 32 countries or regions that met the requirement threshold as five. The size of circles in Figure 4 reflected a total number of records and the distance between the countries indicated the strength of relationships. The VOSviewer divided these circles into four clusters. The different colors group represented the different clusters formed by sets of countries.

According to Figure 4, the first cluster consisted of fourteen countries or regions (red colour) including Russia, Spain, Switzerland, Austria, Portugal, Ireland, Scotland, Germany, Denmark, Poland, Czech Republic, Slovenia, Sweden and Belgium. The second cluster consisted of eight countries or regions (green colour) including South Korea, Canada, Peoples R China, USA, Japan, Norway, Iran and Malaysia. The third cluster consisted of seven countries (blue colour) including France, Australia, Netherlands, New Zealand, Estonia, Brazil and England. The fourth cluster consisted of three countries and regions (yellow colour) including Italy, Finland and Mexico. More cooperation could bring more advanced achievements in scientific research. Nowadays, increasing concept of international exchanges have promoted academic communications (Tang et al., 2018).

\section{Organizations co-authorship analysis}

A total of 694 organizations had the all 302 publications. Organization co-authorship analysis reflected the degree of communication between institutions as well as the influential institutions in this field (Reyes-Gonzalez, 2016). Table 5 represented the top twelve organizations and institutions ranked by the number of total publications (more than nine papers), the total link strength, citations, average citations and country. 


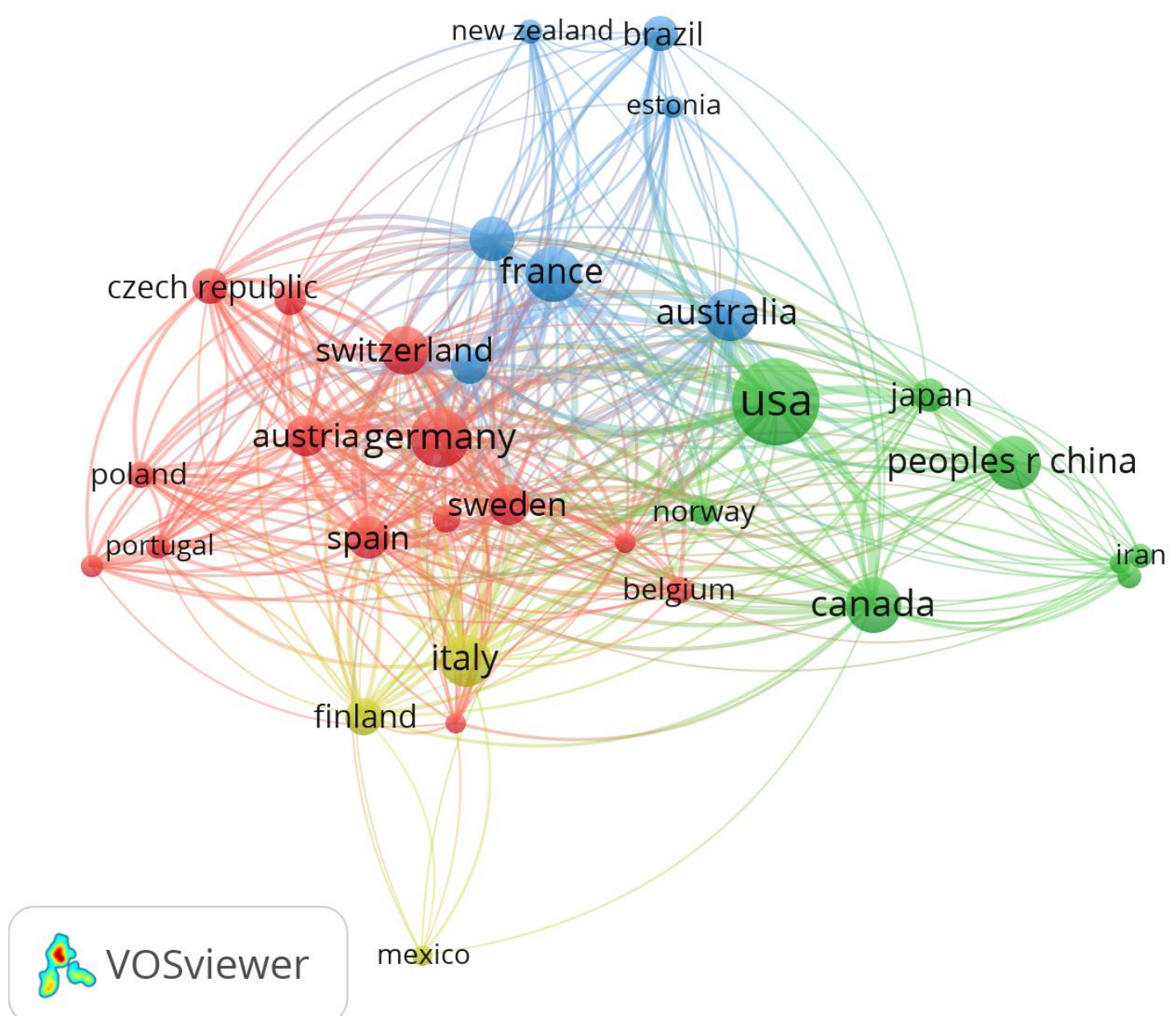

Figure 4. The country co-authorship network of Forestry related top papers from 2010 to 2020.

The country co-authorship network map with 32 nodes and 4 clusters, the bigger nodes represented the more influential countries in this field. The distance and thickness of links represented the degree of cooperation among countries

Table 5. Top 12 organizations published papers in the field of Forestry category from 2010 to 2020

\begin{tabular}{c|c|c|c|c|c|c}
\hline Rank & Organizations & Records & $\begin{array}{c}\text { Total link } \\
\text { strength }\end{array}$ & Citations & $\begin{array}{c}\text { Average } \\
\text { citations }\end{array}$ & Country \\
\hline $\mathbf{1}$ & US Forest Serv & 28 & 22 & 4537 & 162.04 & USA \\
$\mathbf{2}$ & Chinese Acad Sci & 17 & 7 & 2218 & 130.47 & China \\
$\mathbf{3}$ & INRA & 14 & 14 & 3679 & 262.79 & France \\
$\mathbf{4}$ & Swedish Univ Agr Sci & 14 & 19 & 1372 & 98.00 & Sweden \\
$\mathbf{5}$ & Univ Freiburg & 14 & 14 & 1757 & 125.50 & Germany \\
$\mathbf{6}$ & Oregon State Univ & 13 & 30 & 5413 & 416.38 & USA \\
$\mathbf{7}$ & Univ British Columbia & 13 & 9 & 1444 & 111.08 & Canada \\
$\mathbf{8}$ & Univ Calif Berkeley & 11 & 19 & 4930 & 448.18 & USA \\
$\mathbf{9}$ & Nat Resources Canada & 10 & 8 & 1058 & 105.80 & Canada \\
$\mathbf{1 0}$ & Tech Univ Munich & 9 & 13 & 1187 & 131.89 & Germany \\
$\mathbf{1 1}$ & Univ Copenhagen & 9 & 12 & 1100 & 122.22 & Denmark \\
$\mathbf{1 2}$ & Univ Maryland & 9 & 13 & 1015 & 112.78 & USA \\
\hline
\end{tabular}


These twelve organizations were mainly based in USA (four organizations), Germany (two organization), Canada (two organizations), China (1 organization), and France (1 organization), Sweden (1 organization) and Denmark (1 organization). Furthermore, top five organizations of US Forest Serv, Chinese Acad Sci, INRA, Swedish Univ Agr Sci and Univ Freiburg were popular based on contribution of articles more than 14 papers each. Similarly, in case of citation, the top five organizations of Univ Calif Berkeley, Oregon State Univ, INRA, US Forest Serv and Tech Univ Munich showed the higher average citations more than 131.89 times per paper.

Among the total 694 organizations, there were 29 organizations met the minimum thresholds of five, and connected to each other (Fig. 5). The VOSviewer software divided these 29 institutes into four clusters with different colors. Geographical localization is an important factor for partnership and joint venture.

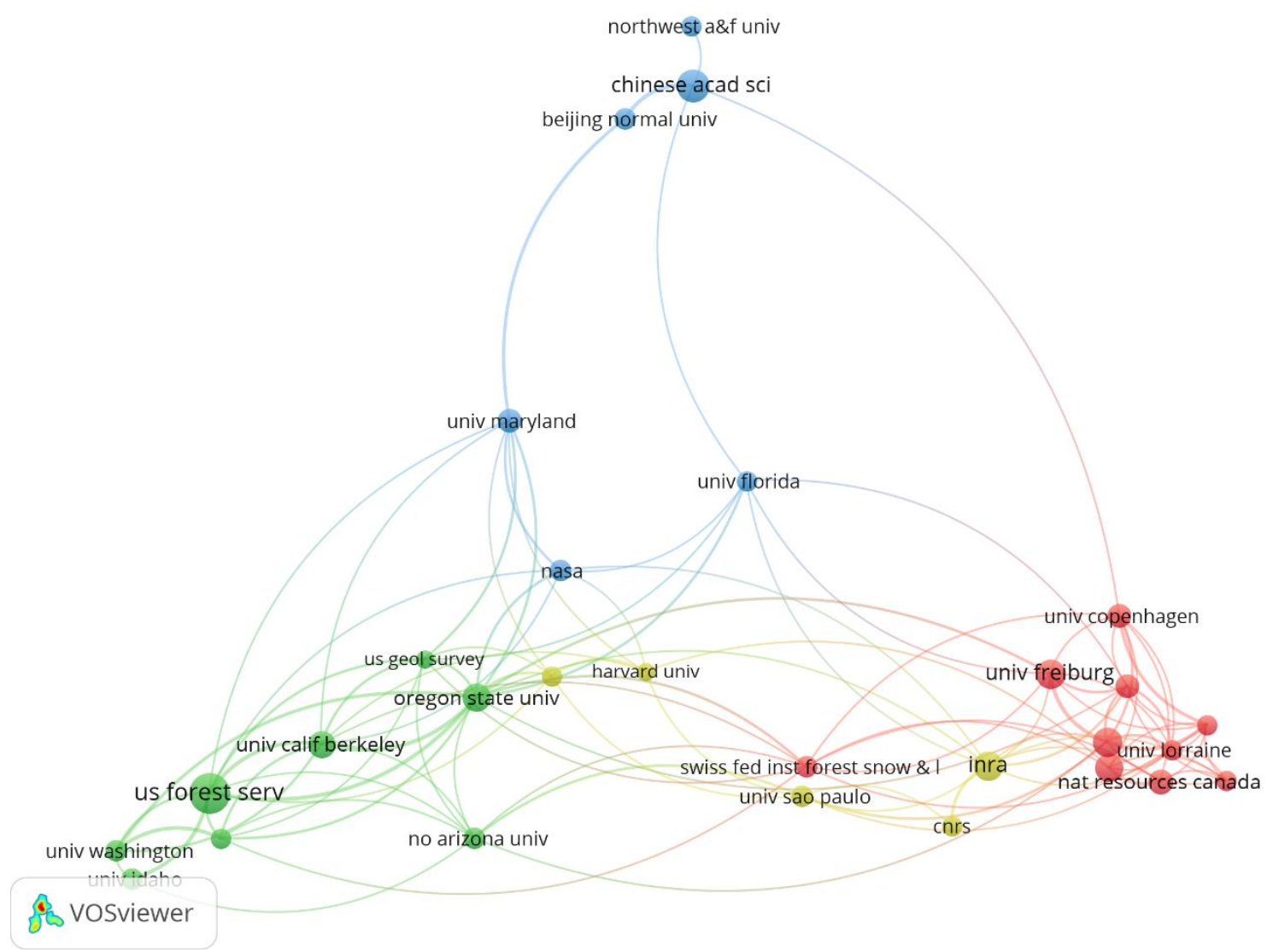

Figure 5. The organizations co-authorship network of Forestry related publications from 2010 to 2020. The institutions co-authorship network map with 29 nodes and 4 clusters, the bigger nodes represented the more influential institution in this field. The distance and thickness of links represented the degree of cooperation among organizations

\section{All keywords co-occurrence analysis}

Figure 6 showed the network map that links the all keywords to the entire sample of the articles analyzed. Among all 2,776 keywords, only 115 keywords met the threshold level of more than five times included in the map. There were seven main clusters that represented different viewpoints on Forestry category research topics (Fig. 6). The top twenty co-occurrence keywords more than eleven times were climate-change, climate 
change, drought, temperature, biodiversity, forest, growth, climate, model, remote sensing, vegetation, management, Scots pine, variability, diversity, Norway spruce, wildfire, area, biomass, conservation, Fagus sylvatica L., stomatal conductance, etc.

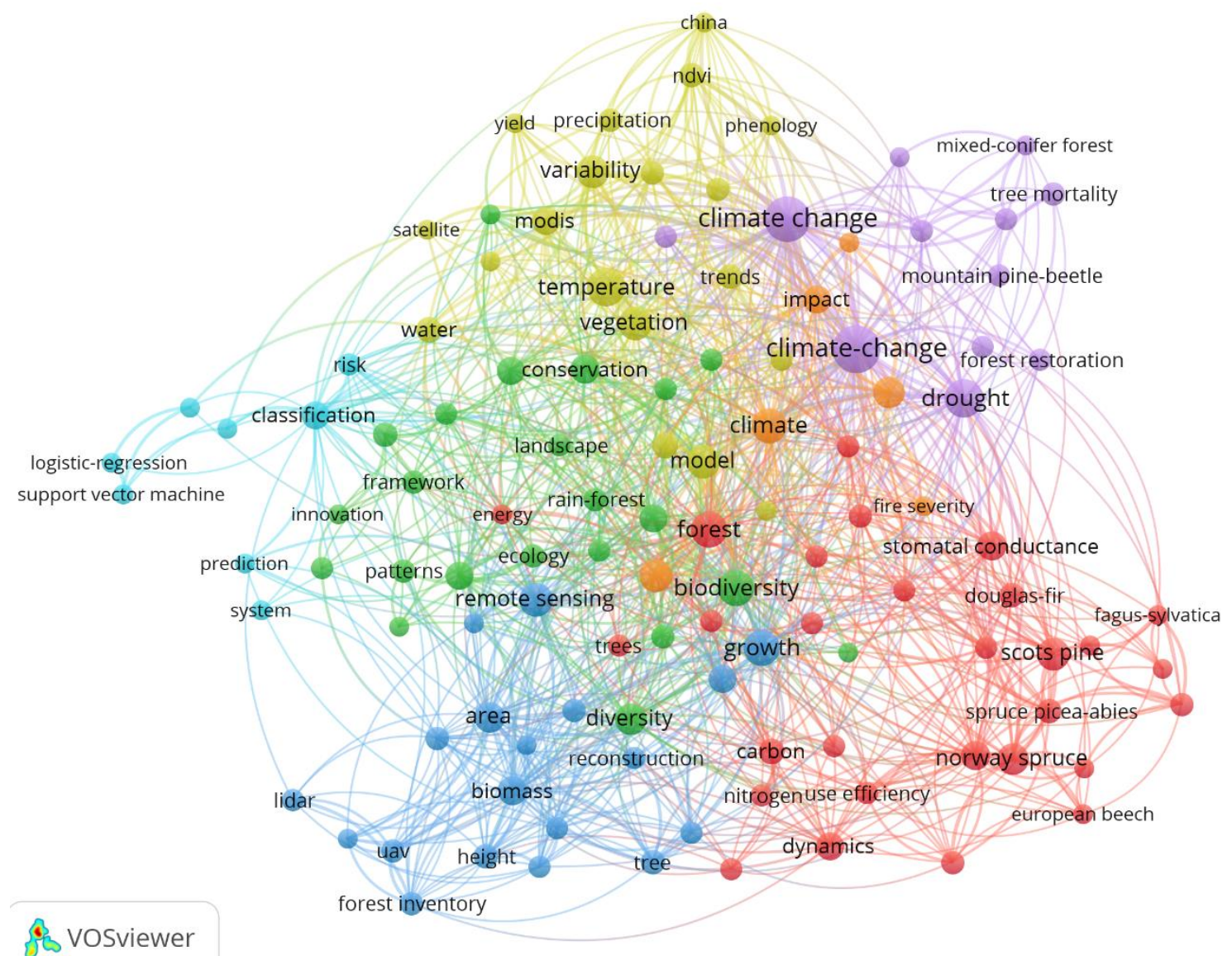

Figure 6. VOSviewer co-occurrence network visualization mapping of most frequent all keywords (minimum of 5 occurrences) in Forestry. Co-occurrence network of all keywords included author keywords and keywords plus. Of the all 2,776 keywords, there were only 115 keywords meet the threshold more than 5 times included in the map. After keywords analyzed, there were 7 main clusters that represent 7 different viewpoints on Forestry

The same data were then arranged by a period of Forestry category research as overlay map (Fig. 7). Blue colors indicated earlier research topics, whereas, yellow and green colors indicated more recent topics of interest. The blue-colored topics did not indicate no longer research work on that topics. It usually indicated that, on average, this topic was intensely investigated earlier and now more attention had shifted towards other topics. Yellow and green circles presented those research fronts.

Visualizations conducted on large datasets (big data) offer exploratory information on the current state in a scientific field or discipline as well as indicated possible developments in the future. Here, the keywords were list and ranked in each cluster based on Figure 6.

The first cluster (Red) focused on dynamics and production of different forests, and included keywords as forest, Scots pine, Norway spruce, Fagus-sylvatica L., stomatal conductance, dynamics, carbon, Douglas-fir, spruce Picea-abies, net primary 
production, temperate forests, water-use efficiency, beech Fagus-sylvatica, carbon sequestration, eddy covariance, elevated $\mathrm{CO} 2$, evaporation, nitrogen, photosynthesis, productivity, transpiration, trees, use efficiency, energy, European beech, Fagussylvatica, long-term, Picea-abies, Pinus-sylvestris, etc.

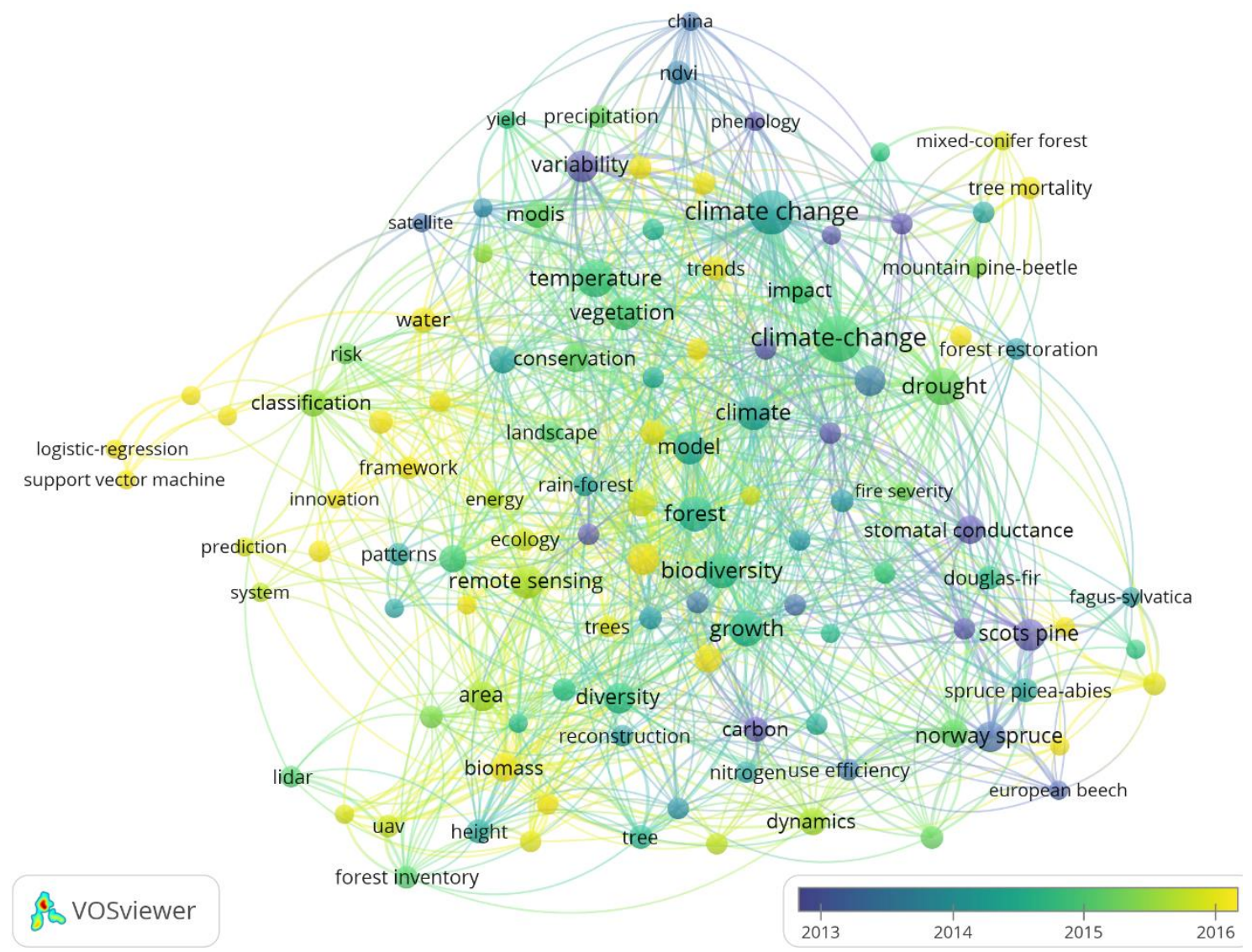

Figure 7. VOSviewer co-occurrence overlay visualization mapping of most frequent all keywords (minimum of five occurrences) in Forestry research from 2010 to 2020

The second cluster (Green) represented the biodiversity of forests and forest management, and included keywords as biodiversity, diversity, conservation, ecosystem services, forests, impacts, policy, ecology, framework, patterns, rain-forest, tropical forest, bioeconomy, decision-making, forest management, landscape, responses, unitedstates, adaptation, innovation, land-use change, species richness, etc.

The third cluster (blue) focused on remote sensing for forest growth, and included keywords as growth, remote sensing, area, biomass, boreal forest, height, tree, forest inventory, forestry, models, UAV, aboveground biomass, airborne lidar, eucalyptus, lidar, reconstruction, cover, density, inventory, etc.

The fourth cluster (yellow) represented temperature and vegetation model, and keywords included as temperature, model, vegetation, variability, modis, land-use, water, NDVI, trends, loess plateau, precipitation, time-series, carbon-dioxide, agriculture, China, leaf area index, phenology, satellite, yield, etc.

The fifth cluster (violet) focused on climate change on forest, and included keywords as climate-change, climate change, drought, tree mortality, ecological restoration, forest 
restoration, mountain pine-beetle, ponderosa pine forests, restoration, soil-moisture, mixed-conifer forest, spatial-patterns, etc.

The sixth cluster (shallow blue) focused on risk classification, keywords were ranked as classification, risk, logistic-regression, machine learning, prediction, random forest, support vector machine, system, etc.

The seventh cluster (orange) focused on the climate management, and keywords were climate, management, wildfire, impact, fire severity, weather, et al.

\section{The most frequently cited articles}

Citation analysis has been employed as a supplementary index to determine the impact of scientific studies, and to identify studies, researchers and the most renowned institutions dealing with the theme. Although a great many articles have been published, a relatively small number of individuals account for a large proportion of the citations within the period. The annual citations of the eight papers showed an increasing trend after year of publication (Fig. 8). The most citations eight papers were written by Allen et al. (2010), Lindner et al. (2010), Colwell et al. (2012), Richardson et al. (2013), Keenan et al. (2015), Rosenzweig et al. (2013), Way and Oren (2010), Sala et al. (2012). Here, the total citations for the most frequently cited articles were more than 417 times. The time dependence of a single paper is called its history. In the beginning year (zero year here), generally the articles have lower citation because of same year of publication.

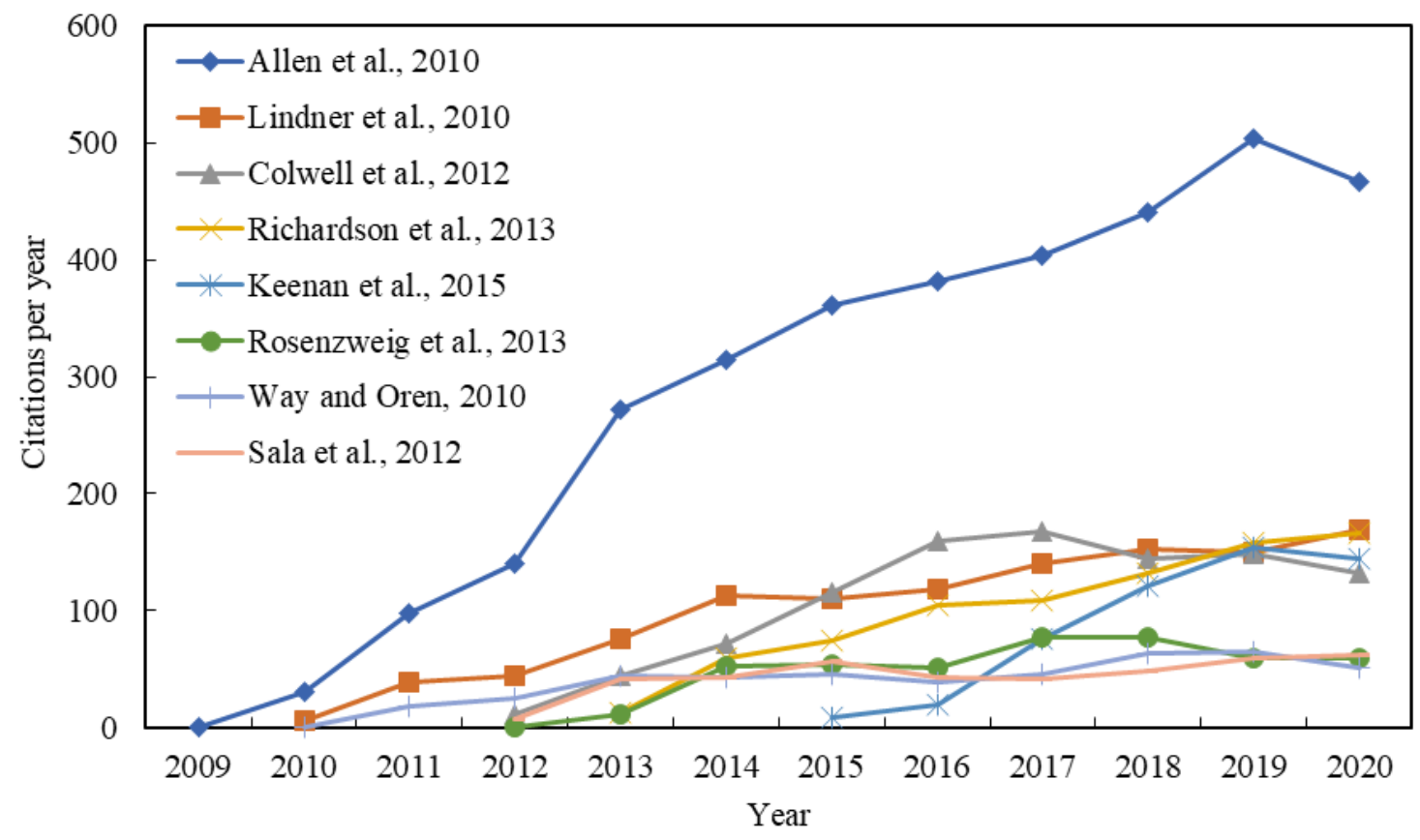

Figure 8. Comparison of the citations per year of the most eight papers from their initial publications to May 1, 2021

From the publication year to May 1, 2021, the average citation per year of the most citation eight papers were 296.92, 97, 102.6, 95.89, 82.29, 51.33, 37.92, and 41.7 times, respectively. From Figure 8, it can be found that the citation per year of the papers 
increased till to 2020, but the increase rate was different each year. Among the eight articles, the highest average citation per year (296.92-blue color) was observed for article of Allen et al. (2010) published in Forest Ecology and Management (Fig. 8).

\section{Conclusions}

This study analyzed 302 top papers in the subject category of Forestry from 2010 to 2020, which included 300 highly cited papers and 3 hot papers in the field. All papers were written in English, from 1,567 authors, 694 organizations and 74 countries or territories, published in 35 journals and book series in the field. The top five Journals were Agricultural and Forest Meteorology, Forest Ecology and Management, Forests, Tree Physiology and Forest Policy and Economics. The top five countries and regions were USA, Germany, Canada, France and Peoples R China. The top five organizations of US Forest Serv, Chinese Acad Sci, INRA, Swedish Univ Agr Sci and Univ Freiburg. Among the all authors, Bauhus, Juergen from Univ Freiburg of Germany gave the most 6 papers. All keywords were separated seven clusters for different research topics. This work is also useful for student identifying graduate schools and researchers selecting journals.

Acknowledgements. This research was supported by the Research Fund Program of Hubei Academic Library Committee (2019-YB-04).

\section{REFERENCES}

[1] Abad-Segura, E., Gonzalez-Zamar, M. D., Vazquez-Cano, E., Lopez-Meneses, E. (2020): Remote sensing applied in forest management to optimize ecosystem services: advances in research. - Forests 11(9): 969. https://doi.org/10.3390/f11090969.

[2] Allen, C. D., Macalady, A. K., Chenchouni, H., Bachelet, D., Mcdowell, N., Vennetier, M., Kitzberger, T., Rigling, A., Breshears, D. D., Hogg, E. H., Gonzalez, P., Fensham, R., Zhang, Z., Castro, J., Demidova, N., Lim, J. H., Allard, G., Running, S. W., Semerci, A., Cobb, N. (2010): A global overview of drought and heat-induced tree mortality reveals emerging climate change risks for forests. - Forest Ecology and Management 259(4 SI): 660-684. https://doi.org/10.1016/j.foreco.2009.09.001.

[3] Aznar-Sanchez, J. A., Belmonte-Urena, L. J., Lopez-Serrano, M. J., Velasco-Munoz, J. F. (2018): Forest ecosystem services: an analysis of worldwide research. - Forests 9(8): 453. https://doi.org/10.3390/f9080453.

[4] Bullock, R., Lawler, J. (2015): Community forestry research in Canada: a bibliometric perspective. - Forest Policy and Economics 59: 47-55. http://dx.doi.org/10.1016/j.forpol.2015.05.009.

[5] Burnard, M., Posavčević, M., Kegel, E. (2017): Examining the evolution and convergence of wood modification and environmental impact assessment in research. iForest 10: 879-885. https://doi.org/10.3832/ifor2390-010.

[6] Chirici, G. (2012): Assessing the scientific productivity of Italian forest researchers using the Web of Science, SCOPUS and SCIMAGO databases. - iForest 5: 101-107. https://doi.org/10.3832/ifor0613-005.

[7] Chuang, K. Y., Wang, M. H., Ho, Y. S. (2011): High-impact papers presented in the subject category of water resources in the Essential Science Indicators database of the Institute for Scientific Information. - Scientometrics 87: 551-562. https://doi.org/10.1007/s11192-011-0365-2. 
[8] Clarivate (2021): Essential Science Indicators Help: About Essential Science Indicators. http://esi.help.clarivate.com/Content/home.htm.

[9] Clarivate (2021): InCites journal citation reports. https://jcr.clarivate.com/JCRLandingPageAction.action.

[10] Colwell, R. K., Chao, A., Gotelli, N. J., Lin, S. Y., Mao, C. X., Chazdon, R. L., Longino, J. T. (2012): Models and estimators linking individual-based and sample-based rarefaction, extrapolation and comparison of assemblages. - Journal of Plant Ecology 5(1): SI 3-21. https://doi.org/10.1093/jpe/rtr044.

[11] Duan, G. Z., Bai, Y., Ye, D. M., Lin, T., Peng, P., Liu, M., Bai, S. L. (2020): Bibliometric evaluation of the status of Picea research and research hotspots: comparison of China to other countries. - Journal of Forestry Research 31(4): 1103-1114. https://doi.org/10.1007/s11676-018-0861-9.

[12] Elango, B., Ho, Y. S. (2018): Top-cited articles in the field of tribology: a bibliometric analysis. - COLLNET Journal of Scientometrics and Information Management 12(2): 289-307. https://doi.org/10.1080/09737766.2018.1529125.

[13] Guerra, A., Reis, L. K., Borges, F. L. G., Ojeda, P. T. A., Pineda, D. A. M., Miranda, C. O., Maidana, D. P. F. D., Dos, S. T., Shibuya, P. S., Marques, M. C. M., Laurance, S. G. W., Garcia, L. C. (2020): Ecological restoration in Brazilian biomes: identifying advances and gaps. - Forest Ecology and Management 458: 117802. https://doi.org/10.1016/j.foreco.2019.117802.

[14] Hirsch, J. E. (2005): An index to quantify an individual's scientific research output. Proc. Natl. Acad. Sci. U.S.A. 102(46): 16569-16572. https://doi.org/10.1073/pnas.0507655102.

[15] Ho, H. C., Ho, Y. S. (2015): Publications in dance field in Arts and Humanities Citation Index: a bibliometric analysis. $\quad$ - Scientometrics 105: 1031-1040. https://doi.org/10.1007/s11192-015-1716-1.

[16] Ho, Y. S. (2014): A bibliometric analysis of highly cited articles in materials science. Current Science 107: 1565-1572.

[17] Ho, Y. S. (2021): A bibliometric analysis of highly cited publications in Web of Science category of emergency medicine. - Signa Vitae 17(1): 11-19. https://doi.org/10.22514/sv.2020.16.0091.

[18] Ivanovic, L., Ho, Y. S. (2019): Highly cited articles in the Education and Educational Research category in the Social Science Citation Index: a bibliometric analysis. Educational Review 71(3): 277-286. https://doi.org/ 10.1080/00131911.2017.1415297.

[19] Keenan, R. J., Reams, G. A., Achard, F., De Freitas, J. V., Grainger, A., Lindquist, E. (2015): Dynamics of global forest area: results from the FAO Global Forest Resources Assessment 2015. - Forest Ecology and Management 352: 9-20. https://doi.org/10.1016/j.foreco.2015.06.014.

[20] Khan, M. A., Ho, Y. S. (2012): Top-cited articles in environmental sciences: merits and demerits of citation analysis. - Science of the Total Environment 431: 122-127. https://doi.org/10.1016/j.scitotenv.2012.05.035.

[21] Khan, A., Khan, D., Akbar, F. (2020): Bibliometric analysis of publications on research into cotton leaf curl disease. - Discoveries 8(2): e109. https://doi.org/10.15190/d.2020.6.

[22] Kolle, S. R., Shankarappa, T. H., Ho, Y. S. (2017): Highly cited articles in Science Citation Index Expanded - subject category of horticulture: a bibliometric analysis. Erwerbs-Obstbau 59: 133-145. https://doi.org/10.1007/s10341-016-0308-4.

[23] Li, Y. Z., Xu, G., Long, X., Ho, Y. S. (2019): A bibliometric analysis of classic publications in web of science category of orthopedics. - Journal of Orthopaedic Surgery and Research 14: 227. https://doi.org/10.1186/s13018-019-1247-1.

[24] Liao, H. C., Tang, M., Li, Z. M., Lev, B. (2019): Bibliometric analysis for highly cited papers in operations research and management science from 2008 to 2017 based on Essential Science Indicators. - Omega-International Journal of Management Science 88: 223-236. https://doi.org/10.1016/j.omega.2018.11.005. 
[25] Lindner, M., Maroschek, M., Netherer, S., Kremer, A., Barbati, A., Garcia-Gonzalo, J., Seidl, R., Delzon, S., Corona, P., Kolstrom, M., Lexer, M. J., Marchetti, M. (2010): Climate change impacts, adaptive capacity, and vulnerability of European forest ecosystems. - Forest Ecology and Management 259(4): 698-709. https://doi.org/10.1016/j.foreco.2009.09.023.

[26] Ma, Q., Li, Y. D., Zhang, Y. (2020): Informetric analysis of highly cited papers in environmental sciences based on essential science indicators. - International Journal of Environmental Research and Public Health 17(11): 3781. https://doi.org/10.3390/ijerph17113781.

[27] Martínez-Santiago, S. Y., Alvarado-Segura, A. A., Zamudio-Sánchez, F. J., CristóbalAcevedo, D. (2017): Spatio-temporal analysis of forest modeling in Mexico. - Revista Chapingo Serie Ciencias Forestales y del Ambiente 23(1): 5-22. https://doi.org/10.5154/r.rchscfa.2016.01.003.

[28] Ordoñez, M. C., Galicia, L. (2020): Bibliometric analysis of models for temperate forest management: a global perspective on sustainable forest management tools. - Revista Chapingo Serie Ciencias Forestales y del Ambiente 26(3): 357-372. http://dx.doi.org/10.5154/r.rchscfa.2019.11.079.

[29] Polinko, A. D., Coupland, K. (2021): Paradigm shifts in forestry and forest research: a bibliometric analysis. - Canadian Journal of Forest Research 51(2): 154-162. https://doi.org/10.1139/cjfr-2020-0311.

[30] Reyes-Gonzalez, L., Gonzalez-Brambila, C. N., Veloso, F. (2016): Using coauthorship and citation analysis to identify research groups: a new way to assess performance. Scientometrics 108: 1171-1191. https://doi.org/10.1007/s11192-016-2029-8.

[31] Richardson, A. D., Keenan, T. F., Migliavacca, M., Ryu, Y., Sonnentag, O., Toomey, M. (2013): Climate change, phenology, and phenological control of vegetation feedbacks to the climate system. - Agricultural and Forest Meteorology 169: 156-173. https://doi.org/10.1016/j.agrformet.2012.09.012.

[32] Romanelli, J. P., Boschi, R. S. (2019): The legacy of elinor ostrom on common forests research assessed through bibliometric analysis. - CERNE 25(4): 332-346. https://doi.org/10.1590/01047760201925042658.

[33] Rosenzweig, C., Jones, J. W., Hatfield, J. L., Ruane, A. C., Boote, K. J., Thorburn, P., Antle, J. M., Nelson, G. C., Porter, C., Janssen, S., Asseng, S., Basso, B., Ewert, F., Wallach, D., Baigorria, G., Winter, J. M. (2013): The agricultural model intercomparison and improvement project (AgMIP): protocols and pilot studies. - Agricultural and Forest Meteorology 170: 166-182. https://doi.org/10.1016/j.agrformet.2012.09.011.

[34] Sala, A., Woodruff, D. R., Meinzer, F. C. (2012): Carbon dynamics in trees: feast or famine? - Tree Physiology 32(6): 764-775. https://doi.org/10.1093/treephys/tpr143.

[35] Stopar, K., Mackiewicz-Talarczyk, M., Bartol, T. (2021): Cotton fiber in web of science and scopus: mapping and visualization of research topics and publishing patterns. $\begin{array}{llll}\text { Journal of } & \text { Natural }\end{array}$ https://doi.org/10.1080/15440478.2019.1636742.

[36] Sun, J., Yuan, B. Z. (2020a): Mapping of the world rice research: a bibliometric analysis of top papers during 2008-2018. - Annals of Library and Information Studies 67(1): 5666.

[37] Sun, J., Yuan, B. Z. (2020b): Bibliometric mapping of top papers in Library and Information Science based on the Essential Science Indicators Database. - Malaysian Journal of Library and Information Science 25(2): 61-76. https://doi.org/10.22452/mjlis.vol25no2.4.

[38] Sun, J., Yuan, B. Z. (2020c): Mapping of top papers in the subject category of Water Resources based on the Essential Science Indicators. - Annals of Library and Information Studies 67(2): 90-102. 
[39] Sun, J., Yuan, B. Z. (2021): Trend and research status of Agronomy based on the Essential Science Indicators during 2009-2019. - Agronomy Journal 113(2): 2184-2194. https://doi.org/10.1002/agj220628.20628.

[40] Tang, M., Liao, H. C., Wan, Z. J., Herrera-Viedma, E., Rosen, M. A. (2018): Ten years of Sustainability (2009 to 2018): a bibliometric overview. - Sustainability 10(5): 1655. https://doi.org/10.3390/su10051655.

[41] Uribe-Toril, J., Ruiz-Real, J. L., Haba-Osca, J., Valenciano, J. D. (2019): Forests' first decade: a bibliometric analysis overview. - Forests 10(1): 72. https://doi.org/10.3390/f10010072.

[42] Van Eck, N. J., Waltman, L. (2010): Software survey: VOSviewer, a computer program for bibliometric mapping. - Scientometrics 84: 523-538. https://doi.org/10.1007/s11192009-0146-3.

[43] Way, D. A., Oren, R. (2010): Differential responses to changes in growth temperature between trees from different functional groups and biomes: a review and synthesis of data. - Tree Physiology 30(6): 669-688. https://doi.org/10.1093/treephys/tpq015.

[44] White-Gibson, A., O'Neill, B., Cooper, D., Leonard, M., O’daly, B. (2019): Levels of evidence in pelvic trauma: a bibliometric analysis of the top 50 cited papers. - Irish Journal of Medical Science 188: 155-159. https://doi.org/10.1007/s11845-018-1818-x.

[45] Xing, Y., Brimblecombe, P. (2020): Trees and parks as "the lungs of cities". - Urban Forestry and Urban Greening 48: 126552. https://doi.org/10.1016/j.ufug.2019.126552.

[46] Yang, D. H., Wang, Y., Yu, T., Liu, X. Y. (2020): Macro-level collaboration network analysis and visualization with Essential Science Indicators: a case of social sciences. Malaysian Journal of Library and Information Science 25(1): 121-138. https://doi.org/10.22452/mjlis.vol25no1.7.

[47] Yeung, A. W. K., Leung, W. K. (2018): Citation network analysis of dental implant literature from 2007 to 2016. - International Journal of Oral and Maxillofacial Implants 33(6): 1240-1246. https://doi.org/10.11607/jomi.6727.

[48] Yuan, B. Z., Sun, J. (2019): Bibliometric and mapping of top papers in the subject category of green and sustainable science and technology based on ESI. - COLLNET Journal of Scientometrics and Information Management 13(2): 269-289. https://doi.org/10.1080/09737766.2020.1716643.

[49] Yuan, B. Z., Sun, J. (2020a): Bibliometric analysis of research on the maize based on top papers during 2009-2019. - COLLNET Journal of Scientometrics and Information Management 14(1): 75-92. https://doi.org/10.1080/09737766.2020.1787110.

[50] Yuan, B. Z., Sun, J. (2020b): Mapping the scientific research on maize or corn: a bibliometric analysis of top papers during 2008-2018. - Maydica 65(2): M17.

[51] Zhang, N., Wan, S. S., Wang, P. L., Zhang, P., Wu, Q. (2018): A bibliometric analysis of highly cited papers in the field of Economics and Business based on the Essential Science Indicators database. - Scientometrics 116: 1039-1053. https://doi.org/10.1007/s11192018-2786-7. 